\title{
Effect of a Residential Integrated Yoga Program on Blood Glucose Levels, Physiological Variables, and Anti-Diabetic Medication Score of Patients with Type 2 Diabetes Mellitus: A Retrospective Study
}

\author{
Amit Singh $^{a} \quad$ Padmini Tekur $^{a} \quad K^{2}$ ashinath Metri ${ }^{a} \quad$ Hemant Bhargav $^{b}$ \\ Nagarathna Raghuram ${ }^{a}$ Nagendra Hongasandra Ramarao $^{a}$ \\ a Swami Vivekananda Yoga Anusandhana Samsthana (SVYASA University), Bengaluru, India; \\ b National Institute of Mental Health and Neurosciences (NIMHANS), Bengaluru, India
}

Keywords

Type 2 diabetes · Integrated yoga $\cdot$ Blood sugar levels $\cdot$ Medication score $\cdot$ Lifestyle

\begin{abstract}
Background: Type 2 diabetes mellitus (T2DM) is a highly prevalent disease characterized by chronic hyperglycemia. Yoga is a form of mind-body intervention shown to have a positive impact on several health conditions in both healthy and diseased patients. The present study is intended to assess the effects of the Residential Integrated Yoga Program (RIYP) on blood glucose levels in patients with T2DM. Material and Methods: Data of 598 (186 females) T2DM patients from a holistic health center in Bengaluru, India, who attended a 15-day RIYP between January 2013 and December 2015 was obtained retrospectively. Average age of the participants was $56.45 \pm 11.02$ years. All subjects underwent a 15-day RIYP which involved yogabased lifestyle changes with components of regulated sleep, balanced diet, asanas, pranayama, relaxation techniques, meditations, yogic cleaning procedures, and tuning to the nature. Fasting and post-prandial blood sugar, medication score, symptom score, systolic and diastolic blood pressure, pulse rate, and respiratory rate were assessed before and after intervention. Result: There was a significant decrease in fasting $(p<0.001)$ and post-prandial blood sugar levels $(p<0.001)$ along with a significant reduction in medication and symptom scores after 15 days of RIYP compared to baseline. Conclusion: The present study indicates that 2 weeks of a yoga-based residential program improves blood glucose levels, blood pressure, and medication score in patients with T2DM. However, further randomized controlled studies need to be performed in order to confirm the present findings.




\section{Introduction}

Type 2 diabetes mellitus (T2DM) is a common metabolic disorder characterized by chronic hyperglycemia. It is a leading cause of morbidity and mortality worldwide, associated with severe complications such as cardiovascular disease, cerebrovascular disease, or chronic renal disease. It is projected to be the 7th leading cause of death by 2030 [1]. The worldwide prevalence of T2DM was estimated to be $6.4 \%$. In Asia, $15 \%$ of the population - or 1 in 7 adults have been reported to have either elevated fasting glucose or impaired glucose tolerance [2], $5-12 \%$ of these persons develop type 2 diabetes every year [3]. At present, India is the country with the 2nd highest number of T2DM patients, and the figure is expected to double by 2030 [4]. The incidence rate of T2DM cases is progressively increasing in rural parts of India, and the age at onset of T2DM is also reducing gradually [5, 6] due to unhealthy lifestyles [7].

Conventional anti-diabetic medication therapy includes oral administration of hypoglycemic agents and insulin therapy. These methods have been shown to be beneficial in the initial phase of T2DM; over a period of time, however, a significant number of patient reports indicate a reduced efficacy of most anti-diabetic medications. Further, these medications are associated with several adverse effects including weight gain $[8,9]$ weakness, fatigue, lactic acidosis, or diarrhea, and they may increase LDL cholesterol level. Vigorous insulin treatment may also carry an increased risk of atherogenesis [10,11].

Yoga is a form of traditional and complementary medicine. Several scientific investigations have shown the health-benefiting effects of yoga in various chronic health conditions including T2DM [12], neuromuscular diseases [13], psychiatric illnesses [14], asthma [15], hypertension [16], and coronary artery disease [17].

\section{Material and Methods}

From a holistic health center in Bengaluru, India, data of 598 (186 females) T2DM patients, with on average $8 \pm 3.4$ years of history of T2DM and who attended a 15-day yoga program between January 2013 and December 2015, was obtained retrospectively.

\section{Inclusion and Exclusion Criteria}

Subjects with T2DM, within the age range of 30-60 years, who meticulously followed the routine of Integrated Approach of Yoga Therapy (IAYT) for 15 days during their stay at the health center, were considered for the study. Subjects were excluded from the study if they were on insulin therapy, had any diabetic complications, were on antipsychotic medication or steroid medication, were long-term practitioners of any kind of yoga, or had been practicing yoga within the last year.

All subjects underwent a 15-day Residential Integrated Yoga Program (RIYP) which involved timetablebased, supervised, yoga-based lifestyle changes with components of regulated sleep, yogic sattvic diet, asanas, pranayama, relaxation techniques, meditations, yoga-based cleansing procedures, lectures on yoga philosophy, and selfless service. All subjects were assessed before and after intervention for changes in fasting blood sugar, post-prandial blood sugar, medication score, and symptom scores along with systolic and diastolic blood pressure, bhramari time, pulse rate, and respiratory rate.

\section{Ethical Considerations}

This study was approved by the institution's Ethics Committee of SVYASA University, Bengaluru, India.

\section{Intervention}

The RIYP which is based on IAYT can be understood as a holistic model, which corrects imbalances at the physical, mental, and emotional level through the application of multiple components such as asanas, diet, loosening exercise, breathing exercises, pranayama, cyclic medication, mind sound resonance technique, devotional sessions, and yogic counseling (lectures). For details on time tables followed during the 15 days of RIYP, see Table 1 and 2. 
Table 1. Details of the special yoga technique for type 2 diabetes mellitus

\begin{tabular}{|c|c|c|c|}
\hline Number & Name & Posture & Practices \\
\hline \multirow[t]{2}{*}{1} & \multirow[t]{2}{*}{ Breathing practices (5 min) } & Standing & Hands stretch breathing \\
\hline & & Sitting & $\begin{array}{l}\text { Rabbit breathing } \\
\text { Tiger stretch breathing }\end{array}$ \\
\hline \multirow[t]{4}{*}{2} & \multirow[t]{4}{*}{$\begin{array}{l}\text { Loosening practices } \\
\text { Shitihilikarana vyayamah } \\
(5 \mathrm{~min})\end{array}$} & Standing & $\begin{array}{l}\text { Padahastasana-Ardha chakrasana vyayama } \\
\text { Trikonasana vyayama } \\
\text { Kati parivartana vyayama (spinal twist) }\end{array}$ \\
\hline & & Sitting & $\begin{array}{l}\text { Chakki chalana } \\
\text { Bhunamanasana }\end{array}$ \\
\hline & & Supine & Pawanmuktasana kriya \\
\hline & & Prone & Dhanurasana swing \\
\hline 3 & Relaxation(5 min) & & Instant relaxation technique \\
\hline 4 & Surya namaskara (5 min) & & 12 steps \\
\hline \multirow[t]{5}{*}{5} & \multirow[t]{4}{*}{ Asanas (10 min each) } & Standing & $\begin{array}{l}\text { Ardhakati chakrasana } \\
\text { Parivrtta trikonasana }\end{array}$ \\
\hline & & Sitting & $\begin{array}{l}\text { Vakrasana } \\
\text { Ardha matsyendrasana }\end{array}$ \\
\hline & & Prone & $\begin{array}{l}\text { Bhujangasana } \\
\text { Dhanurasana }\end{array}$ \\
\hline & & Supine & $\begin{array}{l}\text { Pawanmuktasana } \\
\text { Matsyasana }\end{array}$ \\
\hline & Relaxation (10 min) & & Deep relaxation technique \\
\hline 6 & Kriyas & & Kapalabhati, vaman dhauti (once a week) \\
\hline 7 & Pranayama (10 min) & & $\begin{array}{l}\text { Nadi shuddhi } \\
\text { Bhramari pranayama } \\
\text { Om chanting }\end{array}$ \\
\hline 8 & Meditation (20 min) & & Cyclic meditation \\
\hline
\end{tabular}

Data Analysis

Data was analyzed using IBM SPSS software, version 10. Paired-sample $t$ test was applied to assess changes from pre- to post-RIYP in all variables. Data was presented in the form of mean and standard deviation. Statistical change with a $p$ value $<0.05$ was considered as a significant change.

\section{Results}

\section{Blood Glucose Level (Table 2)}

A significant decrease in post-prandial blood sugar (from $202.79 \pm 77.29$ to $192.24 \pm$ $79.62 ; p<0.001$ ) as well as fasting blood sugar levels (from $156.95 \pm 84.82$ to $134.26 \pm 51.46$; $p<0.001$ ) along with a significant reduction in anti-diabetic medication (from $4.76 \pm 3.30$ to $3.88 \pm 3.20 ; p<0.001$ ) and symptom score (from $156.95 \pm 84.82$ to $134.26 \pm 51.46 ; p<0.001$ ) was found after 15 days of RIYP compared to baseline. 
Table 2. Changes in variables after 15 days of Residential Integrated Yoga Program (RIYP) in patients with type 2 diabetes mellitus

\begin{tabular}{|c|c|c|c|c|c|c|}
\hline \multirow[t]{2}{*}{ Variables } & \multirow{2}{*}{$\begin{array}{l}\text { Pre-RIYP value, } \\
\text { mean } \pm \text { SD }\end{array}$} & \multirow{2}{*}{$\begin{array}{l}\text { Post-RIYP value, } \\
\text { mean } \pm \text { SD }\end{array}$} & \multirow[t]{2}{*}{ df } & \multicolumn{2}{|c|}{ Difference $(95 \% \mathrm{CI})$} & \multirow[t]{2}{*}{$p$ value $^{\mathrm{a}}$} \\
\hline & & & & lower & upper & \\
\hline Pulse rate, bpm & $79.63 \pm 9.24$ & $60.93 \pm 27.79$ & 597 & 86.12 & 55.82 & $<0.001$ \\
\hline Respiratory rate, bpm & $18.28 \pm 3.71$ & $15.66 \pm 4.38$ & 597 & 16.839 & 20.556 & $<0.001$ \\
\hline Systolic BP, mm Hg & $126.81 \pm 18.08$ & $108.08 \pm 24.46$ & 597 & -37.371 & -30.482 & $<0.001$ \\
\hline Diastolic BP, mm Hg & $74.6 \pm 10.45$ & $63.13 \pm 31.53$ & 597 & 15.37 & 20.365 & $<0.001$ \\
\hline Medication score & $4.76 \pm 3.30$ & $3.88 \pm 3.20$ & 597 & 19.313 & 23.623 & $<0.001$ \\
\hline FBS, mg/dL & $156.95 \pm 84.82$ & $134.26 \pm 51.46$ & 597 & -47.055 & -35.645 & $<0.001$ \\
\hline PPBS, mg/dL & $202.79 \pm 77.29$ & $192.24 \pm 79.62$ & 597 & -28.974 & -16.394 & $<0.001$ \\
\hline
\end{tabular}

BP, blood pressure; df, degree of freedom; FBS, fasting blood sugar level; PPBS, post-prandial blood sugar level.

${ }^{\text {a }}$ Paired-sample $t$ test.

\section{Physiological Variables (Table 2)}

Paired-sample $t$ test revealed a significant decrease in systolic (from $126.81 \pm 18.08$ to $108.08 \pm 24.46 ; p<0.001$ ) and diastolic blood pressure (from $74.6 \pm 10.45$ to $63.13 \pm 31.53$; $p<0.001$ ), pulse rate (from $79.63 \pm 9.24$ to $60.93 \pm 27.79 ; p<0.001$ ), and respiratory rate (from $18.28 \pm 3.71$ to $15.66 \pm 4.38 ; p<0.001$ ).

\section{Discussion}

The present study showed a significant improvement in blood glucose levels, physiological variables, and anti-diabetic medication score following 15 days of RIYP in patients with T2DM. This suggests a potential role of RIYP in T2DM management. Yoga-based lifestyle intervention is a comprehensive intervention and consists of several physical and mental practices. Yoga is also cost effective and easy to maintain, requiring little in the way of equipment or professional personnel, and there is evidence indicating excellent long-term adherence and benefits.

A randomized controlled trial by Nagarathna et al. [18], in 2012, showed a significant reduction in oral hypoglycemic medication requirement and LDL; and increasing HDL, blood glucose, HbA1c, triglyceride, total cholesterol, and VLDL following a yoga-based lifestyle modification program.

In our study, T2DM patients stayed for 15 days during which the RIYP for diabetes was imparted to them. Yoga-based lifestyle takes into consideration the 5 important factors of lifestyle: (1) diet, (2) physical activity, (3) sleep, (4) habits, and (5) psychological stress. The designed RIYP was developed to address each of these lifestyle factors and bring balance at all the levels. Medication compliance and adherence to yoga was controlled by the medical doctor and yoga therapist in charge at the section; diet was controlled as standard sattvic food was provided; the location of our health home - being away from city life and amidst nature - could be considered as a calming factor to combat stress.

Many previous studies have shown beneficial effects of yoga in improving overweight, blood pressure, insulin levels, triglycerides [19], fasting and post-prandial blood sugar levels, and pulse rate $[20,21]$. Most of the above-mentioned studies where yoga therapy was beneficial in reducing blood sugar levels involved yoga intervention of discrete yoga sessions (asanas, paranayama, or both) in the usual routine (mostly for 60 min per day, 1-5 days per 
week) and the duration of intervention ranged from 6 weeks to 6 months. In our study, we observed similar effects in a much shorter period of 2 weeks. This suggests that if different components of yoga (viz., asanas, pranayama, meditations, relaxations, devotional sessions, study of the scriptures, and yogic counseling) are integrated together on the basis of the philosophy of yoga-based lifestyle then they may act synergistically and thereby provide better results than those produced by any of the components of yoga alone.

The improvement in fasting and post-prandial blood sugar levels following IAYT may be attributed to an activation of the HPA axis through a reduction in stress which is associated with decreased glucose levels in T2DM. Several sessions of yoga in a day may help the patients to improve their glucose level.

Though the present retrospective study was performed on a large number of T2DM subjects, the lack of a control group is a major limitation of the current study. Future studies should use a control group, where subjects follow a conventional lifestyle change program in a residential setup and then compare the residential conventional lifestyle change program with the residential yoga-based lifestyle program (RIYP).

\section{Conclusion}

The present study indicates that 2 weeks of yoga-based residential program improves blood glucose levels, blood pressure, and medication score in T2DM patients.

\section{Acknowledgement}

We are thankful to all type 2 diabetes patients who participated and all the therapist and doctors involved in the therapy in this study.

\section{Disclosure Statement}

The authors declare no conflicts of interest.

\section{References}

1 World Health Organization (WHO): Global health risks - mortality and burden of disease attributable to selected major risks. Cancer. 2017 Feb 3.

2 Hu G, Qiao Q, Silventoinen K, Eriksson JG, Jousilahti P, Lindström J, Valle TT, Nissinen A, Tuomilehto J: Occupational, commuting, and leisure-time physical activity in relation to risk for type 2 diabetes in middle-aged Finnish men and women. Diabetologia 2003;46:322-329.

3 Santaguida PL, Balion C, Hunt D, Morrison K, Gerstein H, Raina P, Yazdi H: Diagnosis, prognosis, and treatment of impaired glucose tolerance and impaired fasting glucose. Evid Rep Technol Assess (Summ) 2005;128:1-11.

4 International Society for Pediatric and Adolescent Diabetes: IDF/ISPAD 2011 Global Guideline for Diabetes in Childhood and Adolescence. Berlin, International Society for Pediatric and Adolescent Diabetes, 2011.

5 Misra P, Upadhyay RP, Misra A, Anand K: A review of the epidemiology of diabetes in rural India. Diabetes Res Clin Pract 2011;92:303-311.

6 Mohan V, Sandeep S, Deepa R, Shah B, Varghese C: Epidemiology of type 2 diabetes: Indian scenario. Indian J Med Res 2007;125:217.

7 Temelkova-Kurktschiev T, Stefanov T: Lifestyle and genetics in obesity and type 2 diabetes. Exp Clin Endocrinol Diabetes 2012;120:1-6.

8 Dorababu M, Prabha T, Priyambada S, Agrawal VK, Aryya NC, Goel RK: Effect of Bacopa monniera and Azadirachta indica on gastric ulceration and healing in experimental NIDDM rats. Indian J Exp Biol 2004;42:389397.

9 Halim M: Lowering of blood sugar by water extract of Azadirachta indica and Abroma augusta in diabetes rats. Indian J Exp Biol 2003;41:636-640. 
10 Zia T, Hasnain SN, Hasan SK: Evaluation of the oral hypoglycaemic effect of Trigonella foenum-graecum L. (methi) in normal mice. J Ethnopharmacol 2001;75:191-195.

11 Ribes G, Sauvaire Y, Costa CD, Baccou JC, Loubatieres-Mariani MM: Antidiabetic effects of subtractions from fenugreek seeds in diabetic dogs. Proc Soc Exp Biol Med 1986;182:159-166.

12 Chimkode SM, Kumaran SD, Kanhere VV, Shivanna R: Effect of yoga on blood glucose levels in patients with type 2 diabetes mellitus. J Clin Diagn Res 2015;9:CC01.

13 Garfinkel MS, Singhal A, Katz WA, Allan DA, Reshetar R, Schumacher HR Jr: Yoga-based intervention for carpal tunnel syndrome: a randomized trial. JAMA 1998;280:1601-1603.

14 Miller JJ, Fletcher K, Kabat-Zinn J: Three-year follow-up and clinical implications of a mindfulness meditationbased stress reduction intervention in the treatment of anxiety disorders. Gen Hosp Psychiatry 1995;17: 192-200.

15 Nagarathna R, Nagendra HR: Yoga for bronchial asthma: a controlled study. Br Med J (Clin Res Ed) 1985;291: 1077-1079.

16 Metri KG, Pradhan B, Nagendra HR: Impact of short-term residential yoga-based lifestyle intervention on cognitive function in hypertensive patients. J Stem Cells 2017;12:33.

17 Manchanda SC, Narang R, Reddy KS, Sachdeva U, Prabhakaran D, Dharmanand S, Bijlani R: Retardation of coronary atherosclerosis with yoga lifestyle intervention. J Assoc Physicians India 2000;48:687-694.

18 Nagarathna R, Usharani MR, Rao AR, Chaku R, Kulkarni R, Nagendra HR: Efficacy of yoga-based life style modification program on medication score and lipid profile in type 2 diabetes - a randomized control study. Int J Diabetes Dev Ctries 2012;32:122-130.

19 Yang L, Brozovic S, Xu J, Long Y, Kralik PM, Waigel S, Epstein PN: Inflammatory gene expression in OVE26 diabetic kidney during the development of nephropathy. Nephron 2011;119:e8.

20 Amita S, Prabhakar S, Manoj I, Harminder S, Pavan T: Effect of yoga-nidra on blood glucose level in diabetic patients. Indian J Physiol Pharmacol 2009;53:97-101.

21 Singh S, Malhotra V, Singh KP, Sharma SB, Madhu SV, Tandon OP: A preliminary report on the role of yoga asanas on oxidative stress in non-insulin dependent diabetes mellitus. Indian J Clin Biochem 2001;16:216220. 